\title{
Construções de verbos transitivos-predicativos em português: uma perspetiva transformacional
}

\author{
Jorge Baptista \\ Universidade do Algarve - Faculdade de Ciências Humanas e Sociais \\ INESC- ID Lisboa - Human Language Technologies Lab
}

\begin{abstract}
This article presents a proposal for the analysis of transitive-predicative verbal constructions, not derivable transformationally from completive constructions. The theoretical framework of operator-transformational grammar and the methodological principles of the reference framework of the Lexicon-Grammar are adopted herein. The article identifies a set of constructions and distinguishes them from other structures, usually identified as transitive-predicative structures in the literature.
\end{abstract}

Keywords: European Portuguese, verb, transitive-predicative constructions, lexicon-grammar, transformation

Palavras-chave: Português europeu, verbo, construções transitivas-predicativas, léxico-gramática, transformação

\section{Introdução}

As chamadas construções transitivas-predicativas constituem um desafio à descrição das construções verbais em português. Este artigo apresenta uma proposta de análise de algumas destas construções. Trata-se, sobretudo, de frases como (1)-(3):

(1) O Pedro chamou João ao filho

(2) O Pedro chamou o filho de João

(3) O Pedro nomeou o João (como/para) diretor da empresa

e que representam a maioria das construções aqui tratadas. Nestas frases, há uma relação entre os complementos que, grosso modo, se poderia parafrasear por frases como (i) ou (ii):

(i) O filho do Pedro é João $1 /$ O filho do Pedro chama-se João / O filho do Pedro é chamado de João

(ii) $O$ João é diretor da empresa

A estas construções juntam-se ainda outras, como os seguintes exemplos (4)-(5), embora com uma extensão lexical menor:

(4) O Pedro armou-se em defensor dos fracos

(5) $O$ Pedro apareceu como defensor dos fracos

\footnotetext{
* Comunicação apresentada ao XXXVI Encontro Nacional da Associação Portuguesa de Linguística, 28-30 de outubro de 2020.

${ }^{1}$ Note-se que o valor do chamado predicativo nesta frase se altera com a inserção de artigo: $O$ filho do Pedro é o João, deixando de denotar o nome dado para apenas exprimir a correspondência entre as duas entidades.
} 
a que correspondem frases como (iii):

\section{(iii) O Pedro é (o/um) defensor dos fracos}

A correspondência semântica entre o predicativo das construções (1)-(5) e as paráfrases com construções predicativas não é perfeita: em (1)-(2) chamar é 'dar nome' a alguém, enquanto em (i) encontramos a relação 'ter nome'; em (3) nomear para um cargo não implica como em (ii) 'ter' ou 'ter aceite um cargo'; em (4)-(5), por fim, armar-se em e aparecer como implicam que o sujeito poderá, de facto, não ser um defensor dos fracos. ${ }^{2}$

Algumas destas construções ilustradas em (1)-(3) são habitualmente integradas nas construções com os verbos chamados transitivos-predicativos (como o faz, por exemplo, o Dicionário Terminológico ${ }^{3}$ ), considerando que neste tipo de construção os verbos apresentam uma estrutura com 3 constituintes: um sujeito, um complemento direto e um complemento dito predicativo do complemento direto; esta última classificação resultaria de a relação entre os complementos ser considerada equivalente a uma frase do tipo (i) ou (ii), ou seja, uma construção com verbo copulativo e predicativo do sujeito.

Estas construções correspondem, em parte, ao que outros autores (Marrafa, 1993; Paiva Raposo, 2013: 1292 ss., 1340 ss.) chamam de predicação secundária. Paiva Raposo (2013: 1293) inclui especificamente as construções como a do verbo considerar, aqui referida, a que chamará verbos de crença (p. 1346 ss.), mas trata ainda outras construções complexas no quadro da predicação secundária, nomeadamente (exemplos do Autor; em contra-itálico assinala-se o constituinte predicativo):

(a) estruturas adjetivais com pôr: $O$ barulho pôs a Maria louca, que, na sequência de Gross (1981), analisamos como redução de construções adjetivais (A Maria ficou louca) sob este verbo-operador causativo (ver adiante);

(b) estruturas preposicionais com função de adjunto adverbial: O pai chegou a casa com uma péssima disposição, que, na sequência de Ranchhod (1990), analisamos a partir da concatenação da frase da oração principal com uma construção com nome predicativo (disposição) e verbo-suporte estar com (O pai estava com uma péssima disposição), por meio de uma gerundivização, (entendida como uma forma de subordinação adverbial); e, de forma análoga,

(c) construções adjetivais ditas com função de predicativo do complemento direto: $O$ namorado encontrou a Joana no bar completamente bêbeda, que analisamos de modo semelhante como resultado da redução da frase adjetival de base (A Joana estava completamente bêbeda) no quadro de uma frase complexa (idêntica análise poderia, aliás, ser feita para o complemento locativo no bar).

Outros exemplos dados pelo autor (p.1294) relevam de processos semelhantes. O autor indica ainda (pp.1294-5) um conjunto de construções ditas infinitivo preposicionado, que constituem outros casos de predicação secundária, a saber:

\footnotetext{
2 Agradeço a um dos revisores anónimos que chamou a atenção para a necessidade de explicitar estas distinções. O facto de estas construções não se deixarem parafrasear tão facilmente é, parece, um argumento suplementar para as distinguir de outras construções, geralmente integradas nas estruturas transitivas-predicativas, as quais, essas sim, são transformacionalmente analisáveis e mantêm, de forma muito mais clara, o significado das frases elementares de tipo predicativo com que se constroem.

${ }^{3}$ Doravante, DT: http://dt.dge.mec.pt. Este dicionário alista entre os verbos transitivos-predicativos (quando define o conceito de predicativo do complemento direto) os seguintes: achar, chamar, considerar, julgar, tratar, eleger e nomear. Ainda que ciente do caráter didático/pedagógico deste instrumento, parece óbvio que estes verbos não constituem um conjunto sintática e semanticamente homogéneo, como veremos, pelo que a sua eficácia educativa parece sair, neste aspeto, diminuída.
} 
(d) adjuntos adverbiais expressos por orações infinitivas introduzidas por $a$, ora com função de predicativo do sujeito (As crianças chegaram a casa a resmungar com a mãe), ora de predicativo do complemento direto (Vimos as crianças a saltar o muro);

(e) estruturas com deixar ( $O$ filme deixou toda a gente a dormir), que envolvem igualmente um verbo-operador causativo e cuja relação com orações gerundivas, como as apresentadas pelo autor e que não repetimos aqui, por necessidade de brevidade, poderá justificar a sua análise transformacional por meio da operação de gerundivização.

(f) construções com verbos de perceção como sentir (Os meninos sentiram-se a afundar), caso em que é possível analisar a construção com pronome reflexo por redução de uma completiva (Os meninos sentiram-se a afundar/afundando = Os meninos $s_{\mathrm{i}}$ sentiram que (eles $\mathrm{s}_{\mathrm{i}}$ ) estavam a afundar/afundando).

Por limitações de espaço, não se desenvolve mais aqui estes aspetos, já que não se relacionam diretamente com as construções (1)-(5) e nenhuma das análises acima se aplica a estas construções.

Ora, o desafio na descrição das construções do tipo (1)-(5) advém de estas configurações serem homólogas à de outras estruturas que também apresentam o assim chamado predicativo do complemento direto, como as exemplificadas em (6)-(7):

(6) O Pedro acha/considera/julga o João um bom candidato ao cargo

(7) $O$ Pedro acha/considera/julga-se um bom candidato ao cargo

Nestes casos, porém, a relação entre os complementos pode ser explicitada através de uma oração completiva finita, onde reencontramos a frase com verbo copulativo e o chamado predicativo do sujeito:

(6a) O Pedro acha/considera/julga que o João é um bom candidato ao cargo

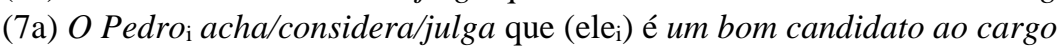

Note-se que em (7b) a presença de um pronome correferente ao sujeito do verbo da oração principal é facultativa e que o pronome pode, no entanto, ter uma interpretação distinta, equivalente à pronominalização do sujeito de uma frase como (6a).

Por sua vez, as orações completivas finitas (6a)-(7a) são equivalentes às orações infinitivas (6b)-(7b) ${ }^{4}$ :

(6b) O Pedro acha/considera/julga ser o João um bom candidato ao cargo

(7b) O Pedro ${ }_{\mathrm{i}}$ acha/considera/julga ser (ele $\mathrm{e}_{\mathrm{i}}$ ) um bom candidato ao cargo

Ao processo transformacional que estabelece a relação entre as frases (6)-(6a)-(6b) e (7)-(7a)-(7b) chamamos redução de completiva. Neste quadro de análise, propõe-se considerar as frases do tipo de (6) e (7) não como formas sintáticas da base da gramática (no sentido de Harris, 1991), mas como formas derivadas a partir das construções com completiva finita, do tipo de (6a) e (7a), passando pela etapa intermédia da redução da completiva finita a infinitiva, a que correspondem as frases do tipo de (6b) e (7b), um processo a que outros autores chamaram de desfinitização (Casteleiro, 1981: 245 ss.; Baptista 2005: 82, 214 ss.). Além da óbvia identidade de significado entre as frases, há várias razões para considerar que elas se encontram relacionadas por um processo transformacional (Gross 1975):

\footnotetext{
${ }^{4}$ As construções infinitivas estão bem atestadas: Quando está com alguém que acha ser a pessoa certa para si, pensar em estar com outras pessoas não é normal. cp. [você] acha que alguém é a pessoa certa para si. Fonte: https://sol.sapo.pt/artigo/585002/ [2017/10/17].
} 
(i) os elementos envolvidos são meros elementos gramaticais: uma conjunção integrante que, que se reduz; um verbo copulativo, que pela desfinitização perde as marcas temporais e, posteriormente se reduz; um pronome, obrigatoriamente correferente ao sujeito do verbo principal, inicialmente facultativo e que posteriormente se reduz;

(ii) a distribuição lexical dos elementos plenamente significativos (achar/considerar/julgar e candidato) é a mesma ao longo da transformação;

(iii) a operação formal é de uma grande generalidade, sendo as condições formais genéricas para a sua aplicação explicitamente enunciáveis (construções com completiva-objeto finita no indicativo), sem prejuízo de outras restrições léxico-sintáticas aplicáveis.

Ora, nenhuma das construções (1)-(5) admite a paráfrase por uma construção completiva, como se vê nas sequências seguintes:

*O Pedro chamou/chama que João era/é o filho; *O Pedro chamou/chama João ser o filho

*O Pedro chamou/chama que o filho era/é João; *O Pedro chamou/chama o filho ser João

* O Pedro nomeou que o João era/é (como/para) diretor da empresa;

* O Pedro nomeou o João ser (comolpara) diretor da empresa

* O Pedro $\mathrm{i}_{\mathrm{i}}$ armou que $\left(\mathrm{ele}_{\mathrm{i}}\right.$ ) era (em) defensor dos fracos;

*O Pedro armou(-se/ele $_{\mathrm{i}}$ ) ser (em) defensor dos fracos

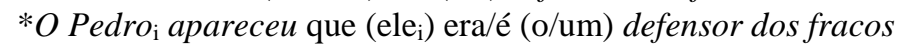

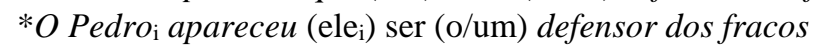

Este artigo propõe distinguir, do conjunto de verbos ditos transitivos predicativos, os verbos como os de (1)-(5), que alistamos numa única classe de construções verbais, dos verbos do tipo de (6)-(7), com completiva no complemento direto, bem como de outras construções com um constituinte a que tradicionalmente se chama predicativo do complemento direto. Para tal, o conceito de transformação sintática, tal como é conceptualizado no quadro da gramática transformacional de operadores harrissiana (Harris, 1991), bem como a abordagem sistemática ao léxico e à gramática, inspirada nos trabalhos de Gross (1975), revelam-se ferramentas fundamentais, permitindo observações relevantes para a teoria da gramática.

Esta proposta resulta de um projeto de descrição sistemática das frases elementares de núcleo predicativo verbal do português europeu contemporâneo, que conduziu à recente publicação do Dicionário Gramatical de Verbos do Português (doravante, DGVP; Baptista \& Mamede, 2020a). Este dicionário foi elaborado a partir de uma base de dados linguísticos (doravante ViPEr), em que foi feita uma descrição formal de cerca de 7.000 construções verbais distintas, distribuídas por cerca de 70 classes léxico-sintáticas (Baptista, 2012, 2013). Tratou-se de formalizar para cerca de 5.500 lemas de verbos frequentes as propriedades sintáticas das suas construções mais usuais, nomeadamente: o número e tipo de argumentos (natureza nominal ou oração completiva); as preposições que introduzem os complementos; a natureza distribucional dos argumentos (humano/não-humano, etc.); o tipo de completiva (finita/infinitiva, factiva, etc.); e as principais propriedades transformacionais (pronominalização, passiva, nominalização/adjetivalização) de cada construção. Por sua vez, a descrição de construções verbais está integrada no projeto mais abrangente de elaboração de um léxico-gramática do português que abrange já as construções verbais fixas (Galvão et al., 2019), construções nominais (Baptista \& Mamede, 2020b) e construções adverbiais (Palma, 2009; Fernandes, 2011).

O artigo está organizado do seguinte modo: em primeiro lugar (\$2), delimitamos o léxico de construções que classificamos na classe 39x do DGVP/ViPEr, e apresentamos a sua subclassificação formal; em seguida (§3), descrevemos as principais propriedades sintático-semânticas associadas a estas construções; (§4) finalmente, contrastamos os verbos desta classe com construções completivas e outras que permitem a 
formação de predicativo do complemento direto; (\$5) o artigo conclui-se com uma breve síntese das observações realizadas.

\section{Léxico dos verbos transitivos-predicativos}

No léxico-gramática dos verbos do português europeu contemporâneo (Baptista \& Mamede, 2020a), a classe 39x é constituída por 76 entradas léxico-sintáticas, sendo possível distinguir entre elas as seguintes subclasses:

39T construções transitivas diretas (65 entradas), com dois complementos, com a estrutura ${ }^{5}$ $N_{0} V N_{1}\left(\right.$ Prep $\left._{2}\right) N_{2}$, de que fazem parte adjetivar, batizar, classificar, designar, eleger, indigitar, nomear, tomar e tratar; é possível, por sua vez, organizar esta subclasse em diferentes subconjuntos de predicados semânticos;

$39 \mathrm{~S}$ construções intrinsecamente pronominais (reflexas) (9 entradas), com um complemento, $N_{0} V_{-}$ se $\left(\right.$ Prep $\left._{2}\right) \mathrm{N}_{2}$, em que se incluem arvorar-se, assumir-se, autoproclamar-se, estabelecer-se, intitular-se e perfilar-se.

A estes dois conjuntos de verbos juntam-se a construção de chamar (39D), já ilustrada em (1), e a construção de aparecer (39I), que encontramos em (5).

Nas linhas que se seguem descrevemos cada uma destas classes (e as duas construções singulares) com mais pormenor.

\subsection{Classe 39T}

A classe 39T pode ser organizada em subconjuntos distintos, tomando como principal critério o papel semântico dos diferentes argumentos do verbo, cuja combinação dá origem a diferentes perfis semânticos. Para o conjunto de papéis semânticos, cuja definição iremos dando à medida que os formos introduzindo no texto, baseamo-nos em Talhadas et al. (2014), que adotámos na elaboração do ViPEr e do DGVP.

\section{(i) construções com sujeito agente-locutor.}

É o conjunto mais numeroso, com 32 verbos, cujo sujeito é estritamente humano e desempenha o papel de agente-locutor; este papel semântico pode ser definido como aquele que é desempenhado pelo sujeito de um verbo de comunicação de tipo declarativo (e.g. afirmar, declarar) ${ }^{6}$. A maioria dos complementos ditos predicativos desempenham um papel que, na falta de melhor designação, chamámos etiqueta, isto é, uma

\footnotetext{
${ }^{5}$ As notações aqui empregues procuram ser transparentes: $N_{\mathrm{i}}$ representa as posições argumentais do verbo, e os índices asua função na construção de base: $N_{0}$ o sujeito, $N_{1}$ e $N_{2}$ os complementos; Prep 2 a preposição que introduz o $2^{\circ}$ complemento; e $V$, o verbo. As transformações são assinaladas entre parênteses retos, e.g. [Passiva ser]; os papéis semânticos e os códigos de classes léxico-sintáticas são destacados a negrito. As classes distribucionais são representadas entre chevrons, e.g. 〈cargo〉. Os elementos facultativos são indicados entre parênteses curvos. As expressões marcadas com asterisco ‘*' são consideradas inaceitáveis e as marcadas com '?' são de aceitabilidade duvidosa. Nos exemplos, expressões alternativas aparecem ligadas por '/'; o símbolo 'E', nestes casos, indica o elemento vazio da comutação, ou, dito de outro modo, a possibilidade de redução/elipse desse elemento. Destacamos nos exemplos em itálico os elementos principais (verbo, sujeito e complementos, e a preposição, quando exista). Quando não se trata de exemplos construídos, e salvo indicação em contrário, todos os outros foram retirados do corpus CETEMPúblico (Rocha \& Santos, 2002), eventualmente truncados por questões de espaço, indicando-se o respetivo extrato: https://www.linguateca.pt/CETEMPublico/.

${ }^{6}$ As construções dos verbos de comunicação, com sujeito agente-locutor, foram objeto de outra comunicação ao XXXVI Encontro Nacional da APL.
} 
expressão que denota a denominação, designação, classificação ou o epíteto dado ao elemento na posição de complemento direto. Quanto a este último complemento, podemos distinguir:

(a) as construções com complemento direto não-humano objeto e predicativo introduzido por de: denominar, intitular (e também titular, mas mais raro):

par=ext276377-clt-95a-1: A esse título, nada é mais revelador que tenha intitulado a sua obra [...] de «A Criação do Mundo» .

par=ext571132-nd-95a-1: Li [...] o texto que o colunista titulou de «A culpa da vítima» .

par=ext61787-nd-94a-2: Também Ana Cristina J. Santos denominou de «calhaus com olhos» [...] ]os seus colegas $[\ldots]$.

(b) as construções com complemento direto humano paciente e predicativo introduzido por de ou como: alcunhar, apelidar, apodar, cognominar, epitetar, tachar:

par=ext528863-clt-94a-2: Ellington era um «gentleman», por isso o alcunharam de Duque...

par=ext448700-clt-93a-1: [...] os admiradores [...] passaram a apodar o seu antigo ídolo de hipócrita, oportunista e espia.

par=ext642959-soc-96b-2: D. João VI, que espírito benevolente cognominou de «Clemente», [...]

par=ext63705-soc-98a-1: [...] uma ponte em metal, que Gomes epitetou de «obra de artista» [...].

par=ext1334221-clt-96b-1: Quando se tacha de «ignorantes» colegas de ofício, o caso muda de figura .

Deste conjunto faz também parte a construção, de uso predominantemente jurídico:

par=ext1230797-soc-95b-2: $O$ autor [...] acabaria por ser pronunciado como arguido [...].

par=ext206489-pol-92b-2: Seria [...] um erro pronunciar a CEI como um nado-morto .

(c) as construções com complemento direto humano paciente e predicativo introduzido por para ou como (mas não de), denotando um cargo ou função, tais como apontar, designar, indigitar, (re)nomear:

par=ext14-pol-97a-2: [...] a Frente Nacional, que prospera sempre a apontar o imigrante como bode expiatório e [...] como a fonte de todos males do povo francês.

par=ext1140794-pol-93a-2: [...], caso Mitterrand o indigitasse como primeiro-ministro.

par=ext32764-nd-96b-2: [...] João Paulo II designou Ortega como primeiro cardeal cubano [...] .

(d) outras construções, cujo complemento direto pode ser preenchido por nome humano paciente ou nome não-humano objeto, com complemento direto humano paciente e predicativo introduzido por de (algumas vezes como, mas não para), como, por exemplo, adjetivar, apelidar, batizar, chamar, qualificar, rotular e tratar:

par=ext241275-pol-92a-2: [...] o Presidente [...] adjectivou um tal programa de «perigoso» .

par=ext22958-clt-97b-1: [...] apelidava Sartre de «imbecil» .

par=ext28020-pol-95a-2: Daí que os chineses já os tenham baptizado de carros-pão . 
Construções de verbos transitivos-predicativos em português: uma perspetiva transformacional

par=ext324-pol-92b-2: Margot, a quem os alemães de leste chamavam de «bruxa», [...].

par=ext3894-pol-94b-1: [...] aquilo que um [...] académico qualificou como o «crime do século» .

par=ext79250-soc-91b-1: [...] outros povos [...] podem rotular os cristãos como «supersticiosos» [...]

par=ext144-pol-95a-1: [...] o [...] clube [...] tratou o Sporting como «um clube terceiro-mundista» [...]

cp. O Presidente adjetivou o programa (de/?como/*para) perigoso ${ }^{7}$

[alguém] apelidava Sartre (de/?como/*para) perigoso

Os chineses batizaram [esses veículos] (de/?como/*para) carros-pão

Os alemães chamavam Margot (de/?*como/*para) bruxa

Um certo académico qualificou aquilo (de/?como/*para) o crime do século

Esses povos rotularam os cristãos (de/?como/*para) supersticiosos

O clube tratou o Sporting (de/?como/*para) terceiro-mundista

(ii) construções com sujeito causa / agente-causa: consagrar, sagrar; lançar.

Trata-se de construções com complemento direto humano e cujo sujeito pode receber uma interpretação de causa, que representamos pelo conceito de nome não restrito (Nnr), adotando-o a partir de Gross (1975):

par=ext30853-clt-92a-1: [...] a divina Rita Hayworth, aqui no papel que a consagrou definitivamente como uma das presenças femininas mais sensuais [...]

par=ext341344-des-97a-1: A primeira semana do circuito masculino sagrou também como vencedor o australiano Todd Woodbridge .

O sujeito de algumas destas construções pode, também, ser preenchido por um nome humano com papel de agente:

par=ext7309-pol-97a-2: [...] Luís Filipe Menezes [...], que foi ao hotel [...] para lançar o nome de Leonor Beleza como potencial candidata à Câmara do Porto. ${ }^{8}$

par=ext273388-nd-91a-1: Picasso lançou a pomba como símbolo do pacifismo comunista [...].

É mais difícil caracterizar distribucionalmente as posições sintáticas de complemento direto e do chamado predicativo. Todos estas construções apresentam obrigatoriamente a preposição como:

Esse papel consagrou Rita (*E/como) uma das presenças mais sensuais

$O$ circuito masculino sagrou o australiano (*E/como) vencedor

LFM lançou o nome de LB (*E/como) potencial candidata à Câmara

Picasso lançou a pomba (*E/como) símbolo do pacifismo

\footnotetext{
${ }^{7}$ Ainda que alguns destes exemplos como como pareçam menos naturais, as frases destes verbos com predicativo introduzido por como estão suficientemente bem atestadas, exceto o verbo chamar.

${ }^{8}$ Naturalmente, trata-se de uma construção figurada de lançar. A combinação lançar-nome, numa situação correspondente a uma proposta de nomeação está particularmente bem atestada no corpus (56 ocorrências), podendo considerar-se uma combinatória com um grau de associação elevado, estatisticamente relevante.
} 
(iii) sujeito experimentador e um complemento direto que pode ser preenchido por nome humano paciente ou nome não-humano objeto, e o predicativo introduzido por como (mas não de nem para), tais como, conceber, conhecer, reconhecer, tomar e ver:

par=ext52514-clt-98a-1: [...] George Gruntz sempre concebeu a sua carreira musical como uma obra aberta $[\ldots]$

par=ext31857-soc-92b-1: [...] visão aterradora para quem conheceu este enorme espaço como local de recolha de hidroaviões [...]

par=ext2743-pol-95b-1: [...] para que Washington reconheça Taiwan como um país livre [...].

par=ext31545-nd-96a-1: Qualquer árabe tomaria este comentário como uma ofensa [...].

par=ext28609-soc-98a-1: Não consigo ver a Expo como parte de Lisboa.

\subsection{Classe 39S}

A classe 39S, mais reduzida (9 entradas), é definida pela propriedade de se tratar de construções intrinsecamente pronominais (ou reflexas: Vse), isto é, em que o verbo surge construído obrigatoriamente com um pronome reflexo que não pode ser substituído por um grupo nominal não correferente ao sujeito nem pode ser reduzido:

Na Estónia, [...] e o país autodeclarou-se como o primeiro Estado digital [...] ${ }^{9}$

* O país autodeclarou a outra nação como o primeiro Estado digital

Este pequeno conjunto de verbos poderia, eventualmente, ser considerado um subconjunto da classe anterior, pois estas construções partilham várias propriedade, desde logo o facto de predominantemente se tratar de verbos com sujeito estritamente humano, na maioria agente-locutor e complemento predicativo introduzido por em, e.g. alvorar-se e arvorar-se; ou por como, e.g.: autodeclarar-se, autodenominar-se e autoproclamar-se; e, mais raramente, por de, e.g. intitular-se:

[...] acho incrivel um tal de luis ferreira alvorar se em supra sumo da verdade $[\ldots]^{10}$

par=ext156776-nd-95b-2: Em nome de que Portugal $o$ dr. Cavaco se arvora em arauto?

par=ext220773-des-92a-2: Como entender então que a Liga se autoproclame como defensora da moralidade dos clubes [...]

par=ext1272963-eco-98a-1: [...] aquele que se autodenomina como presidente da CAP [...]

par=ext1018167-opi-96b-1: Caçadores há que, intitulando-se de «desportistas» [...].

Apenas estabelecer-se e perfilar-se não apresentam precisamente este perfil, já que selecionam um sujeito agente genérico (mas não um locutor):

par=ext19784-soc-93b-2: Este jovem [...] conseguiu estabelecer-se como consultor financeiro [...]. par=ext73781-des-97a-1: Checos [...] perfilam-se como os principais opositores.

\footnotetext{
${ }^{9}$ https://oficialdejustica.blogs.sapo.pt/o-envelhecimento-traz-rugas-visiveis-495202 [2021-06-20].

${ }^{10} \mathrm{https}: / /$ www.record.pt/ (num comentário a notícia de 2002-08-15) [2021-06-20].
} 


\section{Propriedades léxico-sintáticas dos verbos transitivos-predicativos}

Nesta secção apresentamos as propriedades léxico-sintáticas mais salientes das construções com verbos transitivos-predicativos da classe 39x.

\subsection{Propriedades distribucionais}

A maioria das construções alistadas em 39x apresenta, como se viu, sujeito humano, com papel semântico de agente-locutor. Dado o significado destas frases, o elemento sobre o qual o chamado predicativo é dito (sujeito ou complemento direto) é muito menos restrito, admitindo frequentemente um nome de tipo humano e não humano nessa posição. Quanto ao predicativo, destacam-se os verbos que, nessa posição de predicativo admitem de forma mais específica um nome próprio (v.g. alcunhar, apelidar, batizar, chamar, nomear e tratar):

\section{O Pedro batizou o filho de João}

o Pedro trata o João por Joninhas

ainda que nos casos de alcunhar e apelidar estes complementos possam ser preenchidos por designações variáveis e não especificamente nomes próprios, mas que funcionam como epítetos ou cognomes do paciente:

\section{O Pedro alcunhou/apelidou o João de "submarino"}

A natureza metalinguística de muitos destes predicados revela-se ainda no emprego frequente de aspas para esta posição argumental, justificando o estabelecimento de um papel semântico específico a que chamámos etiqueta.

Constituem ainda um conjunto interessante de predicados os que selecionam para esta posição um nome de 〈cargo>, de <profissão> ou outro designativo de função (alçar, destituir, eleger, elevar, empossar, entronizar, indigitar, investir, nomear e ordenar). Estes verbos distinguem-se ainda por apresentarem um sujeito agente (e não propriamente um locutor). Aliás, esta restrição distribucional leva-nos a distinguir dois empregos de nomear: o primeiro no sentido mais etimológico de 'dar nome', hoje muito pouco usual, e o segundo, com o valor de 'atribuir/designar para o cargo':

\section{?O Pedro nomeou o filho (de/como) João}

O Pedro nomeou o João como diretor da empresa.

Como noutras situações, observam-se verbos que exprimem predicados altamente especializados, com uma distribuição particularmente restrita da posição de segundo complemento, como é o caso de ordenar, em que encontramos dois paradigmas:

ordenar <nome_próprio> (como) (diácono/ padrel bispo/ cardeall...) e

ordenar $<$ nome_próprio> $($ como $)$ cavaleiro ${ }^{11}$.

\footnotetext{
${ }^{11}$ Nestas construções, o verbo ordenar pode ser substituído por fazer: O papa fê-lo bispo; O rei fê-lo cavaleiro. Tratamos aqui fazer como um pro-verbo, isto é, um verbo de valor genérico que substitui outro de significado e construção mais preciso. O fenómeno não parece ocorrer com mais nenhuma outra construção desta classe.
} 
Jorge Baptista

Já com elevar, a par do emprego em que estão envolvidos nomes de cargos ou similares, encontramos o emprego especializado aplicado a localidades e o seu estatuto jurídico-administrativo:

O Pedro elevou o João a diretor da empresa

A Assembleia da República elevou <topónimo> a (cidade/ vila; (sede de) freguesial concelho)

A par de elevar encontra-se o verbo menos usual alçar.

Os verbos cujo sujeito (humano) é interpretado como experimentador (conceber, conhecer, contar, dar, encarar, reconhecer, tomar, ver) estão muito próximos das construções de verbos de perceção mental (classe 06, do ViPEr/DGVP), aliás alguns poderão ser considerados desdobramentos dessa construção com completiva objeto; note-se, porém, que o significado das duas construções é suficientemente distinto para as autonomizar no léxico-gramática:

O Pedro vê o João como um inimigo a abater (39T)

O Pedro vê que o João é um inimigo a abater (06)

No caso das construções com sujeito não-restrito (Nnr) com valor de causa, v.g. consagrar, sagrar e lançar, a presença de um sujeito humano agente parece dificilmente aceitável nos primeiros dois casos:

*O Pedro (con)sagrou o João como campeão

ao passo que é bastante mais natural, como vimos, no caso de lançar:

?*O Pedro lançou o João como candidato ao cargo.

\subsection{Propriedades transformacionais}

Como muitas outras construções transitivas diretas, os verbos de 39T admitem a construção passiva, ora com verbo auxiliar ser ora com estar, ora com ambos os verbos:

O João foilestá apelidado/apodado/cognominado/intitulado (como/de) "dragão das Docas"

Este produto foilestá caracterizado/classificado/referenciado como nocivo para a saúde

O rapaz era/*estava chamado de João

O João foilestá apontado/designado/indigitado/nomeado (como/para) diretor da empresa

O João foi/está constituído como arguido (nesse processo)

Obviamente, as construções intrinsecamente pronominais (reflexas) de 39S não permitem esta operação, nem a construção de chamar em que o complemento direto desempenha o papel de etiqueta, v.g. O Pedro chamou "cobarde" ao João.

Analisamos como construções passivas pronominais (com -se) um pequeno conjunto de construções em que o paciente/objeto ocorre em posição de sujeito e o constituinte com o papel de etiqueta aparece muitas vezes sem preposição:

O rapaz chama-se $(*$ de) João

(cp. Alguém chama o rapaz de João) 
O João sagrou-se (como) campeão

(cp. Isso sagrou o João (como) campeão)

O João contava-se (como) o seu melhor amigo

(cp. O Pedro conta o João (como) o seu melhor amigo)

O João contava-se entre os seus melhores amigos

(cp. O Pedro conta o João entre os seus melhores amigos)

O quadro intitula-se (comolde) "Primavera cinzenta"

(cp. Alguém intitulou o quadro (como/de) "Primavera cinzenta")

Naturalmente, a interpretação destas construções nem sempre é evidente, já que algumas se deixam analisar como construções reflexas:

O Pedro caracterizou-se / qualificou-se / proclamou-se como um libertino

O Pedro cognominou-se / epitomou-se / proclamou-se de "grande libertino do Bairro Alto"

ou como construções com sujeito indefinido -se, e.g. Batizou-se o menino (como/de/E $\left.{ }^{12}\right)$ João.

Analisemos agora o estatuto do elemento que introduz o complemento (como, de, para), que iremos tratar como preposição. Uma das propriedades mais salientes destas construções é um número interessante (cerca de um terço) que admite a redução da preposição como sem alteração do significado:

A Rainha armou Sean Connery (como) cavaleiro

O Pedro designou/nomeou/apontou o João (como/para) seu representante legal

O Pedro autodeclarou-se/autoproclamou-se "Imperador da Culatra"

O MO constituiu o João (como) arguido (neste processo)

As frases passivas destas construções mantêm a possibilidade de redução da preposição:

Sean Conery foi armado (como) cavaleiro (pela Rainha)

O João foi designado/nomeado/apontado (comolpara) representante legal (pelo Pedro)

O João foi constituído (como) arguido (pelo MP neste processo)

Ainda assim, a maioria dos verbos desta classe não permite essa redução, independentemente da seleção de como para introduzir o complemento:

O Pedro adjetivou/ apodou/ qualificou o João (*E/ como / de) mentiroso

O Pedro chamar o João (*E / de) mentiroso

As frases passivas correspondentes apresentam praticamente a mesma inaceitabilidade:

O João foi adjetivado/ apodado/ qualificado (*/*? E / como / de) mentiroso (pelo Pedro)

\footnotetext{
${ }^{12}$ Recorde-se que 'E' representa o elemento vazio da comutação. A redução da preposição origina uma ambiguidade, que não é relevante analisar aqui.
} 
Em certos casos, a inaceitabilidade da expressão reduzida, tanto na forma ativa como na passiva, não parece ser suficientemente clara para a rejeitarmos:

O Pedro batizou a criança (?de) "Leopoldino"

A criança foi batizada (?de) "Leopoldino” (pelo Pedro)

O Pedro denominou o fenómeno (?de) redução de completiva

o fenómeno foi denominado (?de) redução de completiva”" (pelo Pedro)

A redução de preposição que introduz um complemento não é um fenómeno inaudito, observando-se com muitos outros verbos, de diferentes tipos, e.g. namorar/namoriscar (com) alguém 32H/35S), mas ainda é um fenómeno mal conhecido. No caso das construções 39x que a autorizam, contudo, contribui de forma relevante para as aproximar das construções com o chamado predicativo do complemento.

Outro aspeto que explica a proximidade de vários verbos da 39x com as construções transitivas-predicativas prende-se com o facto de, na maioria das construções que aceitam como, se observar a possibilidade de fazer equivaler o predicativo a uma oração gerundiva com verbo copulativo:

O Pedro qualificou esse livro como (sendo) "um disparate pegado"

O Pedro deu esse assunto como (estando) encerrado

Note-se, porém, que o emprego de outra preposição, ainda que autorizada pelo verbo, bloqueia esta paráfrase:

*O Pedro qualificou esse livro de (sendo) "um disparate pegado"

* O Pedro deu esse assunto por (estando) encerrado

Os predicados do tipo de 'nomear/indigitar para cargo' não admitem esta paráfrase, mas aceitam uma infinitiva se o complemento estiver introduzido por para:

O Pedro nomeou o João para (ser/desempenhar o cargo de) diretor da empresa

A natureza deste complemento como uma eventual oração subordinada final e, logo, como adjunto, não é evidente, considerando a equivalência a um grupo nominal. Note-se, ainda, a variação parala fim de, etc. com uma oração finita:

O Pedro nomeou o João parala fim de que (ele) fosse/desempenhasse o cargo de diretor da empresa

que não parece ser totalmente equivalente às construções transitiva-predicativa e infinita.

\section{Construções completivas transitivas-predicativas}

Como se disse na introdução, os verbos da classe 39x não admitem a equivalência a uma construção completiva que permita parafrasear a relação intuitivamente percebida como existente entre os complementos (em 39T) ou entre o sujeito e o complemento (39S). 
O Pedro adjetivou esse livro (como/de) "um disparate pegado"

* O Pedro adjetivou que esse livro era "um disparate pegado"

Mesmo nas construções em que é possível a reconstituição de um verbo copulativo a introduzir o elemento "predicativo", a paráfrase por uma completiva é inaceitável:

O Pedro qualificou esse livro como sendo "um disparate pegado"

* O Pedro qualificou que esse livro era "um disparate pegado"

O Pedro deu esse assunto como estando encerrado

* O Pedro deu que esse assunto estava encerrado

Como se depreende da listagem de verbos incluídos em 39x, alguns subconjuntos até se prestam mal a uma paráfrase "predicativa". Como vimos no início, os verbos do tipo de eleger/ nomear (para um cargo), por exemplo, não implicam que o complemento paciente tenha ou desempenhe esse cargo. Os verbos do tipo de designar/ classificar/ adjetivar relevam mais de uma função metalinguística, num papel semântico que tentamos captar com o termo de etiqueta, do que de uma relação predicativa entre os complementos: chamar a alguém "bruxa" não implica que essa pessoa seja bruxa. Concedemos, porém, que nos casos do tipo de (con)sagrar e lançar é razoável considerar a condição de verdade denotada pelo predicativo (naturalmente dependente do tempo-aspeto-modo) do verbo principal:

O Pedro consagrou-se como campeão (O Pedro é campeão);

O Pedro lançou o João como candidato ao cargo (O João é candidato ao cargo).

Este tipo de considerações, contudo, não nos parece relevarem do foco deste artigo. Pelo menos de um ponto de vista transformacional, estas construções não podem ser consideradas frases complexas ao mesmo título que as frases dos verbos com construções com completiva-objeto, cujos empregos com predicativo do complemento direto é possível fazer derivar por redução de completiva.

Naturalmente, está fora do âmbito deste artigo fazer a descrição dos verbos com completiva-objeto (sobretudo classe 06I do ViPEr; quase 200 entradas) que permitem a sua redução e a formação do chamado predicativo com complemento direto:

O Pedro considera que esse assunto a $_{\mathrm{i}}$ interessante $_{\mathrm{i}}=$ esse $_{\text {assunto }}$ interessante $_{\mathrm{i}}$

$O$ Pedro $_{\mathrm{i}}$ acha que $\left(\right.$ ele $\left._{\mathrm{i}}\right)$ é suficientemente corajoso $\mathrm{i}_{\mathrm{i}}=-\mathrm{se}_{\mathrm{i}}$ suficientemente corajoso $_{\mathrm{i}}$

Esse tópico, de resto demasiado complexo para um mero artigo, terá de ficar para outra ocasião. Limitamo-nos a assinalar que, em muitas destas construções transitivas-predicativas, reencontramos a preposição como a introduzir o chamado predicativo:

O Pedro considera que esse assunto $_{\mathrm{i}}$ é interessante ${ }_{\mathrm{i}}=$ esse $_{\text {assunto }}$ como interessante $_{\mathrm{i}}$

ainda que outros fatores, ainda mal conhecidos, possam condicionar essa paráfrase:

O Pedro acha que o João é corajoso; *O Pedro acha o João como corajoso

mas: O Pedro acha que essas medidas são oportunas; $O$ Pedro acha essas medidas como oportunas 
A aceitabilidade duvidosa da construção transitiva-predicativa com como deverá levar a procurar as condições distribucionais que autorizam essa construção, cuja ocorrência em corpora, de resto, não é difícil comprovar $^{13}$ :

par $=$ ext786821-soc-91b-1: Além disso, sublinha, as entidades intervenientes no processo tomaram «as medidas possíveis e achadas como oportunas [...] .

Numa outra linha de pensamento, referimos, ainda, as construções com verbo operador-causativo (Gross, 1981), um tipo particular de construção verbal, com sujeito não restrito (Nnr) e valor de causa, que, operando sobre construções adjetivais ou construções com nome predicativo e verbo-suporte (Ranchhod 1990; Baptista, 2005), "absorve" o verbo auxiliar adjetival ou o verbo-suporte, deixando o adjetivo ou o nome predicativo na função de predicativo do complemento direto:

A dieta deixou \# O Pedro estava esfomeado = A dieta deixou \# o Pedro esfomeado

A dieta deixou \# O Pedro estava com fome = A dieta deixou \# o Pedro com fome

Nestes casos, como na classe de construções aqui tratada, não é possível encaixar o predicado adjetival ou nominal sob uma completiva:

\section{* A dieta deixou que o Pedro estavalestivesse esfomeado \\ *A dieta deixou que o Pedro estavalestivesse com fome}

Concedemos, obviamente, a estrutura com complemento e predicativo de construções como estas, de resto, também analisadas por Paiva Raposo (2013: 1338). Preferimos, no entanto, e na sequência dos autores referidos acima, considerar que se trata de construções complexas e não um verbal pleno. O verbo-operador causativo $(V o p c)$ funciona, nestas construções, como veículo de um valor gramatical de causa. A estrutura proposta permite fazer a decomposição destas frases nos predicados (lexicais) elementares, isto é, o adjetivo (esfomeado) ou o nome predicativo (fome), e um elemento causativo. Tal dá conta, por exemplo, da manutenção das propriedades gerais desses elementos predicativos apesar da redução do verbo (copulativo ou verbo-suporte). Por exemplo, a seleção da preposição com, que introduz o nome predicativo na construção estar com fome, não se altera sob o Vopc deixar.

A redução - ou 'absorção', para usar o termo de Gross (1981) - do verbo-suporte (ou do verbo copulativo nas construções adjetivais) é uma operação de uma grande generalidade, verificando-se para a maioria das construções com estar Prep (Ranchhod 1990). A ocorrência desta redução, neste caso sob deixar, explica, por exemplo, que o verbo reduzido seja estar (eventualmente uma sua variante aspetual) e não outros verbos-suporte com que o mesmo nome predicativo se constrói (v.g. ter fome); ou que, com outros nomes predicativos, reencontremos apenas as preposições da respetiva construção:

\section{A falta de dinheiro deixou \# O Pedro está em crise = A falta de dinheiro deixou o Pedro em crise}

Aliás, é possível considerar que a distribuição do Vopc é mais função (da construção) do nome predicativo do que uma restrição de seleção imposta pelo próprio verbo, já que se verificam assimetrias surpreendentes, lexicalmente determinadas, quando se comparam as combinatórias de pôr vs. deixar - os dois Vopc principais

\footnotetext{
${ }^{13}$ A construção transitiva-predicativa com como está abundantemente atestada com estes verbos, na internet: “.... só poderei considerar como interessante uma mulher que tenha o que usualmente sinto como "classe" ". (https://delitodeopiniao.blogs.sapo.pt/5066194.html ?thread=44532690, 18/12/2012); “... nas provas que a Direção achar como oportunas...” (https://www.cm-caminha.pt/, 07/06/2017).
} 
a operar sobre as construções com estar - com a lista dos nomes predicativos construídos com verbo-suporte estar Prep.

Também não ignoramos, de resto, outras diferentes situações sintáticas que estarão na origem de estruturas reduzidas em que se forma o chamado predicativo do complemento direto, como o clássico exemplo $O$ Pedro bebeu o chá frio e que podem, com vantagem, ser analisadas num quadro transformacional (e.g. O Pedro bebeu o chá \# estando o chá frio/ [o chá] que estava frio), dando conta, de forma natural da ambiguidade entre interpretação predicativa ou restritiva (Raposo 2013, pp. 1341-4) destes adjetivos.

Ora, é justamente para uma melhor compreensão desses variadíssimos fenómenos que nos parece útil distinguir as construções 39x. Para estas, a análise das formas através dos métodos transformacionais, decompondo as frases complexas nas frases elementares que lhe estão na origem, não parece de todo funcionar. Além disso, para um número importante destas, nem mesmo a paráfrase predicativa parece capturar adequadamente a relação entre os complementos. O fenómeno da redução da preposição (sobretudo como), por seu turno, parece de âmbito limitado, mesmo no quadro desta classe, e lexicalmente dependente não só do verbo principal como do preenchimento lexical das posições argumentais.

\section{Conclusão}

Neste artigo, apresentámos uma delimitação precisa do léxico de construções verbais que classificamos na classe 39x do ViPEr/DGVP (Baptista, 2013; Baptista \& Mamede, 2020a) e que, embora tradicionalmente alinhadas com verbos a que se convencionou chamar transitivos predicativos, deles se distinguem claramente, sobretudo pelo facto de não poderem ser derivadas de construções com completiva-objeto.

Apresentamos, então, a sua subclassificação formal, baseada quer no número de argumentos quer no perfil semântico dessas construções, definido com base na sequência dos papéis semânticos das diferentes posições argumentais. No conjunto de papéis considerados avulta o dos sujeitos agente-locutor, que permite caracterizar de forma mais precisa a natureza comunicativa de bom número destes verbos. A natureza semântica de muitos dos predicados envolvidos levou-nos, também, a propor um papel semântico apropriado a vários destes verbos, um papel semântico a que chamámos etiqueta. Este papel dá conta, entre outros aspetos, da semântica (valor metalinguístico) destes predicados e explica, por exemplo, o uso de aspas a delimitar o predicativo. Foram critérios acessórios, ainda, (i) a seleção das preposições que introduzem o complemento a que se atribui a função de "predicativo" e em que se salienta o emprego de como, que encontramos noutras construções associadas a construções completivas; e (ii) restrições distribucionais mais finas quanto ao preenchimento (e.g. nomes de <cargo , etc.)

Em seguida, descrevemos as principais propriedades sintático-semânticas associadas a estas construções, nomeadamente, (i) os diferentes tipos de passivas e as restrições sobre os respetivos auxiliares; (ii) o fenómeno, que percebemos como circunscrito, de redução da preposição que introduz o complemento e condições em que esta se verifica. Por fim, contrastamos os verbos desta classe com construções completivas (e outras) que permitem a formação de predicativo do complemento direto, podendo, no entanto, este constituinte ser derivado de frases complexas através de diferentes operações de redução.

Naturalmente, haveria mais para dizer. Contudo, julgamos ter atingido o nosso objetivo inicial: a principal contribuição deste estudo consistiu em mapear uma zona do léxico das construções verbais, com base em critérios formais claros e reprodutíveis, numa abordagem sistemática, de natureza taxonómica, solidamente apoiada em evidência retirada predominantemente de corpora (ocasionalmente de exemplos recolhidos da internet).

Doravante, não deverá ser possível amalgamar, como faz o $D T$, num mesmo conjunto os verbos aqui tratados (nomear, designar, chamar, etc.) com outros (achar, considerar, julgar, etc.), como se de uma única 
classe se tratasse. De resto, a minuciosa descrição de Paiva Raposo (2013) provê um riquíssimo conjunto de exemplos e de diversas situações sintáticas envolvendo o conceito de predicação secundária, em diferentes construções com "predicativo", que poderá servir de base a uma investigação sistemática das condições que presidem à formação destas configurações. A sua análise poderá revelar como os métodos transformacionais permitem uma regularização da gramática a partir da decomposição de frases complexas nas frases elementares por que são formadas. Essa análise ficará para outra ocasião.

\section{Agradecimentos}

Parte da investigação para este artigo foi financiada por fundos públicos, pela Fundação para a Ciência e a Tecnologia (UIDB/50021/2020). O Autor agradece aos revisores anónimos cujos comentários, sugestões e correções permitiram melhorar uma versão inicial deste texto, bem como a Sónia Reis uma leitura final do documento.

\section{Referências}

Baptista, Jorge (2005) Sintaxe dos Predicados Nominais com Ser de. Lisboa: Fundação Calouste Gulbenkian/Fundação para Ciência e a Tecnologia.

Baptista, Jorge (2012) ViPEr: A Lexicon-Grammar of European Portuguese Verbs. In. 31e Colloque International sur le Lexique et la Grammaire, Nové Hrady, Czech Republic. pp.10-16.

Baptista, Jorge (2013) ViPEr: uma base de dados de construções léxico-sintáticas de verbos do Português Europeu, In. Fátima Silva, Isabel Falé \& Isabel Pereira (org.) Textos Selecionados, XXVIII Encontro Nacional da Associação Portuguesa de Linguística, Faro, APL, 2013, pp. 111-129,

Baptista, Jorge \& Nuno Mamede (2020a) Dicionário Gramatical de Verbos do Português. Faro: Universidade do Algarve.

Baptista, Jorge \& Nuno Mamede (2020b) Syntactic Transformations in Rule-Based Parsing of Support Verb Constructions: Examples from European Portuguese. In. SLATE. Dagstuhl, pp. 1-11.

Casteleiro, João M. (1981) Sintaxe Transformacional do Adjetivo. Lisboa: INIC.

Fernandes, Gaia O.P. (2011) Automatic disambiguation of -mente ending adverbs in Brazilian Portuguese. Tese de Mestrado, Universidade do Algarve/Universitat Autònoma de Barcelona.

Galvão, Ana, Jorge Baptista \& Nuno Mamede (2019) New developments on processing European Portuguese verbal idioms. In. 12th Symposium in Information and Human Language Technology, pp. 229-238.

Gross, Maurice (1975) Méthodes en syntaxe. Paris: Hermann.

Gross, Maurice (1981) Les bases empiriques de la notion de prédicat sémantique. Langages (63), pp. 7-52.

Harris, Zellig S. (1991) Theory of language and information: a mathematical approach. Oxford: Clarendon Press.

Marrafa, Palmira (1993) Predicação Secundária e Predicados Complexos: Análise e Modelização. Dissertação de doutoramento, Universidade de Lisboa.

Paiva Raposo, Eduardo B. (2013) Orações copulativas e predicações secundárias. In. Eduardo Paiva Raposo et al. (org.) Gramática do Português. Lisboa: Fundação Calouste Gulbenkian, pp. 1285-1357.

Palma, Cristina (2009) Estudo Contrastivo PortuguêsEspanhol de Expressões Fixas Adverbiais, Tese de Mestrado, Universidade do Algarve.

Rocha, Paulo \& Diana Santos (2002) CETEMPúblico: Um corpus de grandes dimensões de linguagem jornalística portuguesa. In. Maria das Graças Volpe Nunes (ed.) Actas do V Encontro para o processamento computacional da língua portuguesa escrita e falada (PROPOR'2000) (Atibaia, São Paulo, Brasil, 19 a 22 de Novembro de 2000), pp. 131-140. 